\title{
Alcohol use among school-going adolescents in Harare, Zimbabwe: results from the 2003 Global School-Based Health Survey
}

\author{
S. SIZIYA ${ }^{1}$, E. RUDATSIKIRA ${ }^{2}$ and A.S. MUULA ${ }^{3 *}$ \\ ${ }^{1}$ Department of Community Medicine, University of Zambia, School of Medicine, Lusaka, Zambia \\ ${ }^{2}$ School of Public Health, Loma Linda University, Loma Linda California, United States \\ ${ }^{3}$ Department of Community Health, University of Malawi, College of Medicine, Private Bag 360, Chichiri, Blantyre 3, \\ Malawi
}

\begin{abstract}
Data from the Global School-Based Health Survey (2003) were analysed to estimate the proportions of relevant socio-demographic and behavioural characteristics. Of the 1997 students who participated in the survey, $15.6 \%$ (17.1\% males and $14.0 \%$ females) reported alcohol consumption. Factors associated with consumption of alcohol use were being worried, bullied, smoking cigarettes, truant, and lack of parental supervision. Students who were never worried were $49 \%$ (AOR=0.51 $[95 \% \mathrm{CI}(0.36,0.72)]$ ) less likely to consume alcohol compared to students who were most of the time or always worried. Similarly, students who were never bullied were $42 \%(\mathrm{AOR}=0.57$ [95\%CI $(0.42,0.77)]$ ) less likely to take alcohol compared to students who were bullied at least six times in the previous one month to the survey. Compared to students who smoked cigarettes, non-smokers were $71 \%(\mathrm{AOR}=0.29$ [95\%CI $(0.21,0.41)])$ less likely to consume alcohol. Compared to students who always received parental supervision, students who rarely received parental supervision were more likely $(\mathrm{AOR}=1.85[95 \% \mathrm{CI}(1.19,2.90)]$ to consume alcohol, and those students who sometimes received parental supervision were less likely $(\mathrm{AOR}=0.70[95 \% \mathrm{CI}(0.50,0.98)]$ to consume alcohol. There is a need to implement public health interventions with special attention to the determinants of alcohol consumption in this age group.
\end{abstract}

Key words: alcohol use, behaviour, school adolescent, Zimbabwe

\section{Introduction}

In the most recent World Health Organization (WHO) Global Burden of Disease report, it was stated that better epidemiological data on substance use were needed, particularly in less established market economies (Degenhardt et al., 2004; Ezzati \& Lopez, 2004). The paucity of data on substance use and an understanding of the relevant risk factors and policy measures are likely to continue due to lower priority that non-communicable diseases garner when compared to infectious diseases. Only two African countries (Nigeria and South Africa) participated in the World Mental Health Survey (WMHS), an initiative of the WHO with the aim of documenting, among other things a comprehensive picture of substance use patterns across the world. The countries which participated in the WMHS were those who had collaborators in the country and were able to obtain funding for the survey. The other 15 countries were Colombia, Mexico, the United States in the Americas, Belgium, France, Germany, Italy, Netherlands, Spain, Ukraine in Europe, Israel and Lebanon in the Middle East, Japan and China in Asia and New Zealand in Oceania.
Despite the limited geographical spread of well conducted surveys on substance use especially in Africa, some data are available in selected countries on use among school going adolescents. The Global Tobacco Surveillance Systems' Global Youth Tobacco Survey (GYTS) and the Global School-Based Health Survey (GSHS) have been key in reducing the lack of knowledge on substance use in African countries.

In a study of rural secondary school students in Zimbabwe, Gwede et al. (2001) reported $29.3 \%$ and $19.3 \%$ lifetime use and previous 30 day use of alcohol, respectively, among the respondents. Males were more likely to have used alcohol than females. In an earlier study of teachers reported by Eide \& Acuda (1999), the teachers had reported that alcohol use was the most common substance used in Zimbabwe, followed by cannabis, tobacco, inhalants and other drugs. In a related paper, these authors reported that $38.6 \%$ of male teachers and $8.2 \%$ of female teachers reported drinking every day or at least weekly (Eide $e t$ al., 1999a).

It is important that we understand the prevalence and associated factors of alcohol use among adolescents. Adolescents who use

\footnotetext{
* Correspondence: Dr. Adamson S. Muula; E-mail: $\underline{\text { muula@email.unc.edu }}$
} 
alcohol may also be engaged in other unhealthy and antisocial behaviors such as unprotected sexual intercourse, tobacco smoking, violence behaviors and truancy (Santelli et al., 1998; Valois et al., 1999). Furthermore, many adolescent substance users continue doing so into adulthood (Pitkänen et al., 2008; Poikolokainen et al., 2001). Clark et al. (2008) have reported that adolescent-onset substance use disorders prospectively predicted early mortality.

In order to contribute to the literature on alcohol use among adolescents in Zimbabwe, we analyzed data from the Harare (the capital city of Zimbabwe) Global School-Based Survey, 2003. The aim of our analysis was to estimate the prevalence of alcohol use, and assess its associated factors. We argue that public health interventions thataredesigned and implemented having considered the epidemiology of alcohol use, are more likely to be effective than if such considerations are not made.

\section{Materials and Methods}

Several authors have previously reported the details about the GSHS (Brown et al., 2008). In brief however, the GSHS is a self-administered, school-based survey that was developed by the WHO in collaboration with the United Nations Children's Fund (UNICEF), the United Nations Educational, Scientific and Cultural Organization (UNESCO), and the Joint United Nations Programme on HIV/AIDS (UNAIDS). Technical and financial assistance was obtained from the US Centers for Disease Control and Prevention (CDC). The survey is aimed at recruiting students aged 13-15 years, and a questionnaire is completed within one regular class period.

In each country where the survey is administered, the questionnaire comprises multiple core questionnaire modules, coreexpanded questions and country-specific questions. A standardized scientific sample selection process and common school-based methodology is implemented. The survey employed a two-stage cluster sample design to obtain a representative sample of students in forms one to three. In the first-stage of sampling, sampling frame consisted of all schools in Harare containing any of the secondary forms one to three. Forms one to three classes were selected because they contained the majority of the target groups i.e. 13 to 15year age groups, within the schools. Schools were selected with probability proportional to school enrollment size i.e. a school with a larger enrollment had a higher probability of being selected than another with a lower school enrollment. A total of 25 schools were eventually selected as eligible to participate in the study.

Using a random start, the second stage of sampling consisted of randomly selecting classrooms. All classrooms selected in the stage one were included in the sampling frame. All students in the sampled classrooms were eligible to participate in the survey. A self-completed questionnaire, using multiple-choice questions, was administered in English. Questionnaires were completed at school within one class period. Protection of the student's privacy is made through anonymous and voluntary participation. To further help protect student privacy, no skip patterns were allowed.

Data were analysed using SPSS version 14.0. We estimated the proportions of relevant socio-demographic and behavioural characteristics. The main outcome of interest was having used alcohol in the 30 days preceding the survey. The question was: 'During the past 30 days, on how many days did you have at least one drink containing alcohol?' Weighted analysis initially with single predictor, and then Backward logistic regression in a multivariate model was conducted. We report unadjusted Odds ratios (OR), and Adjusted Odds Ratios (AOR) with their 95\% Confidence Intervals (CI).

\section{Results}

\section{Characteristics of survey participants}

Altogether 1997 students participated in the survey. About a third (31.3\%) of the students was of age 15 years, and $49.3 \%$ were males. The proportion of students who seriously considered attempting suicide was $21.6 \%$, and that for students who reported being bullied at least once was $53.6 \%$. Overall $6.2 \%$ of the students smoked cigarettes. Alcohol consumption was reported by $15.6 \%$ of the students (17.1\% among males, and $14.0 \% \mathrm{v}$ among females) (Table 1). 
Table 1: Sample description of the survey participants

\begin{tabular}{|c|c|c|c|c|}
\hline Factor & Response & $\begin{array}{l}\text { Total } \\
\mathrm{n}^{*}(\%)^{* *}\end{array}$ & $\begin{array}{l}\text { Male } \\
\mathrm{n}^{*}(\%)^{* *}\end{array}$ & $\begin{array}{l}\text { Female } \\
\mathrm{n}^{*}(\%)^{* *}\end{array}$ \\
\hline \multirow[t]{4}{*}{ Age } & $\leq 13$ & $307(15.8)$ & $121(14.4)$ & $183(17.1)$ \\
\hline & 14 & $531(27.2)$ & $213(25.6)$ & $316(28.8)$ \\
\hline & 15 & $626(31.3)$ & $282(32.0)$ & $340(30.5)$ \\
\hline & $16+$ & $520(25.7)$ & $252(27.9)$ & $266(23.6)$ \\
\hline \multirow[t]{2}{*}{ Sex } & Male & $873(49.3)$ & - & - \\
\hline & Female & $1111(50.7)$ & - & - \\
\hline \multirow[t]{4}{*}{ Felt lonely in past 12 months } & Never & $559(28.9)$ & $258(30.2)$ & $298(27.7)$ \\
\hline & Rarely & $218(11.0)$ & $100(11.5)$ & $115(10.3)$ \\
\hline & Sometimes & $898(45.4)$ & $370(43.5)$ & $522(47.1)$ \\
\hline & time/Always & $286(14.8)$ & $124(14.8)$ & $162(14.9)$ \\
\hline \multirow{4}{*}{$\begin{array}{l}\text { Worried such that could not sleep at night in } \\
\text { past } 12 \text { months }\end{array}$} & Never & $733(37.4)$ & $344(39.5)$ & $386(35.4)$ \\
\hline & Rarely & $263(12.8)$ & $112(12.5)$ & $149(13.0)$ \\
\hline & $\begin{array}{l}\text { Sometimes } \\
\text { Most of the }\end{array}$ & $735(36.8)$ & $308(36.0)$ & $421(37.5)$ \\
\hline & time/Always & $260(13.1)$ & $105(12.0)$ & $153(14.1)$ \\
\hline \multirow[t]{2}{*}{$\begin{array}{l}\text { Sad or hopeless such that stopped doing } \\
\text { usual activities in past } 12 \text { months }\end{array}$} & Yes & $726(36.8)$ & $302(35.1)$ & 419 (38.4) \\
\hline & No & $1228(63.2)$ & $539(64.9)$ & $682(61.6)$ \\
\hline \multirow[t]{2}{*}{$\begin{array}{l}\text { Seriously considered attempting suicide in } \\
\text { past } 12 \text { months }\end{array}$} & Yes & 425 (21.6) & $162(19.4)$ & $260(23.7)$ \\
\hline & No & $1545(78.4)$ & $692(80.6)$ & $843(76.3)$ \\
\hline \multirow[t]{4}{*}{ Number of days bullied in past 30 days } & 0 & $832(46.4)$ & $325(42.9)$ & $503(49.7)$ \\
\hline & 1,2 & $518(29.6)$ & $212(28.5)$ & $305(30.7)$ \\
\hline & 3.5 & $199(11.3)$ & $103(13.7)$ & $94(9.0)$ \\
\hline & $6+$ & $215(12.7)$ & $112(14.8)$ & $101(10.6)$ \\
\hline \multirow[t]{3}{*}{$\begin{array}{l}\text { Number of times in a physical fight in past } 12 \\
\text { months }\end{array}$} & 0 & $1307(64.5)$ & $511(58.8)$ & $792(70.7)$ \\
\hline & 1 & $349(17.8)$ & $181(20.6)$ & $166(15.0)$ \\
\hline & $2+$ & $338(17.6)$ & $179(20.6)$ & $153(14.3)$ \\
\hline \multirow[t]{2}{*}{ Smoked cigarettes in past 30 days } & No & $1792(93.8)$ & $751(91.1)$ & $1032(96.5)$ \\
\hline & Yes & $110(6.2)$ & $73(8.9)$ & $36(3.5)$ \\
\hline \multirow[t]{2}{*}{ Had sexual intercourse in past 12 months } & Yes & $84(4.8)$ & $52(6.7)$ & $30(2.8)$ \\
\hline & No & $1706(95.2)$ & 707 (93.3) & $993(97.2)$ \\
\hline \multirow[t]{3}{*}{ Number of days was truant in past 30 days } & 0 & $1305(67.8)$ & $529(64,9)$ & $771(70.8)$ \\
\hline & 1,2 & $399(20.0)$ & $172(19.8)$ & $223(20.1)$ \\
\hline & $3+$ & $222(12.1)$ & $125(15.3)$ & $96(9.1)$ \\
\hline \multirow[t]{4}{*}{ Number of close friends } & 0 & $208(10.2)$ & $84(9.4)$ & $119(10.6)$ \\
\hline & 1 & $615(31.8)$ & $251(30.2)$ & $363(33.7)$ \\
\hline & 2 & $607(30.1)$ & $230(26.7)$ & $373(33.3)$ \\
\hline & $3+$ & $552(27.9)$ & $295(33.7)$ & $254(22.4)$ \\
\hline \multirow[t]{4}{*}{ Parental supervision in past 30 days } & Never & $321(16.6)$ & $151(18.0)$ & $169(15.4)$ \\
\hline & Rarely & $138(7.0)$ & $66(7.5)$ & $71(6.5)$ \\
\hline & Sometimes & $584(31.3)$ & $254(31.4)$ & $324(30.8)$ \\
\hline & $\begin{array}{l}\text { Most of the time } \\
\text { Always }\end{array}$ & $391(20.5)$ & $160(20.0)$ & $230(21.2)$ \\
\hline \multirow[t]{2}{*}{ Consumed alcohol in past 30 days } & No & $1524(84.4)$ & $645(82.9)$ & $871(86.0)$ \\
\hline & Yes & $279(15.6)$ & $134(17.1)$ & $142(14.0)$ \\
\hline
\end{tabular}


Factors associated with alcohol use among adolescents in Harare

Age, sex, and number of close friends were not significantly associated with alcohol consumption in bivariate analyses. Bivariate analyses showed that students who were never lonely, never worried, not bullied, not involved in a physical fight, non-smokers, and not truant were less likely to consume alcohol. Factors that were positively associated with alcohol intake in bivariate analyses were being sad or hopeless, seriously considered attempting suicide, having had sexual intercourse, and rarely or never had parental supervision (Table 2).

Table 2: Factors associated with alcohol consumption among school going adolescents in Harare

\begin{tabular}{|c|c|c|c|}
\hline Factor & Response & OR (95\%CI) & AOR $(95 \% C I)$ \\
\hline \multirow[t]{4}{*}{ Age } & $\leq 13$ & $1.10(0.85,1.43)$ & \\
\hline & 14 & $0.90(0.72,1.13)$ & - \\
\hline & 15 & $0.97(0.79,1.19)$ & \\
\hline & $16+$ & 1 & \\
\hline \multirow[t]{2}{*}{ Sex } & Male & $1.13(0.99,1.28)$ & \\
\hline & Female & 1 & \\
\hline \multirow[t]{4}{*}{ Felt lonely in past 12 months } & Never & $0.47(0.36,0.62)$ & \\
\hline & Rarely & $1.07(0.79,1.45)$ & - \\
\hline & Sometimes & $1.14(0.93,1.39)$ & \\
\hline & Most of the time/Always & 1 & \\
\hline \multirow[t]{4}{*}{$\begin{array}{l}\text { Worried such that could not sleep at } \\
\text { night in past } 12 \text { months }\end{array}$} & Never & $0.41(0.32,0.53)$ & $0.51(0.36,0.72)$ \\
\hline & Rarely & $1.16(0.89,1.52)$ & $1.15(0.80,1.65)$ \\
\hline & Sometimes & $1.00(0.82,1.22)$ & $0.98(0.74,1.29)$ \\
\hline & Most of the time/Always & 1 & 1 \\
\hline \multirow[t]{2}{*}{$\begin{array}{l}\text { Sad or hopeless such that stopped } \\
\text { doing usual activities in past } 12 \\
\text { months }\end{array}$} & 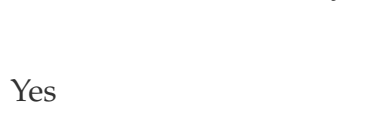 & $1.32(1.15,1.50)$ & \\
\hline & No & 1 & - \\
\hline \multirow[t]{2}{*}{$\begin{array}{l}\text { Seriously considered attempting } \\
\text { suicide in past } 12 \text { months }\end{array}$} & Yes & $1.42(1.23,1.64)$ & \\
\hline & No & 1 & - \\
\hline \multirow{4}{*}{$\begin{array}{l}\text { Number of days bullied in past } 30 \\
\text { days }\end{array}$} & 0 & $0.45(0.36,0.57)$ & $0.57(0.42,0.77)$ \\
\hline & 1,2 & $0.93(0.74,1.16)$ & $1.00(0.75,1.34)$ \\
\hline & 3.5 & $1.15(0.85,1.54)$ & $1.12(0.76,1.67)$ \\
\hline & $6+$ & 1 & 1 \\
\hline $\begin{array}{l}\text { Number of times in a physical fight } \\
\text { in past } 12 \text { months }\end{array}$ & $\begin{array}{l}0 \\
1 \\
2+\end{array}$ & $\begin{array}{l}0.65(0.54,0.77) \\
0.84(0.67,1.06)\end{array}$ & - \\
\hline \multirow[t]{2}{*}{ Smoked cigarettes in past 30 days } & No & $0.21(0.17,0.27)$ & $0.29(0.21,0.41)$ \\
\hline & Yes & 1 & 1 \\
\hline \multirow[t]{2}{*}{$\begin{array}{l}\text { Had sexual intercourse in past } 12 \\
\text { months }\end{array}$} & Yes & $1.97(1.54,2.53)$ & - \\
\hline & No & 1 & \\
\hline \multirow[t]{3}{*}{$\begin{array}{l}\text { Number of days was truant in past } \\
30 \text { days }\end{array}$} & 0 & $0.35(0.29,0.42)$ & $0.55(0.42,0.71)$ \\
\hline & 1,2 & $1.19(0.98,1.46)$ & $1.31(0.98,1.73)$ \\
\hline & $3+$ & 1 & 1 \\
\hline \multirow[t]{4}{*}{ Number of close friends } & 0 & $0.89(0.64,1.24)$ & - \\
\hline & 1 & $0.90(0.72,1.13)$ & \\
\hline & 2 & $0.94(0.75,1.18)$ & \\
\hline & $3+$ & 1 & \\
\hline \multirow[t]{5}{*}{ Parental supervision in past 30 days } & Never & $1.50(1.16,1.93)$ & $1.42(1.00,2.01)^{*}$ \\
\hline & Rarely & $2.22(1.60,3.08)$ & $1.85(1.19,2.90)$ \\
\hline & Sometimes & $0.77(0.61,0.98)$ & $0.70(0.50,0.98)$ \\
\hline & Most of the time & $0.79(0.61,1.04)$ & $0.87(0.61,1.26)$ \\
\hline & Always & 1 & 1 \\
\hline
\end{tabular}

\footnotetext{
* P-value $=0.052$; - factor dropped out of the final model in a Backward logistic regression analysis
} 
Factors that were independently associated with consumption of alcohol were being worried, bullied, smoking cigarettes, truant, and parental supervision. Students who were never worried were $49 \%$ ( $\mathrm{AOR}=0.51$ [95\%CI $(0.36,0.72)])$ less likely to consume alcohol compared to students who were most of the time or always worried. Similarly, students who were never bullied were $42 \%$ (AOR=0.57 [95\%CI $(0.42,0.77)])$ less likely to take alcohol compared to students who were bullied at least six times in the previous one month to the survey. Compared to students who smoked cigarettes, non-smokers were $71 \%$ $(\mathrm{AOR}=0.29$ [95\%CI $(0.21,0.41)])$ less likely to consume alcohol. Students who were not truant were $45 \%(\mathrm{AOR}=0.55$ [95\%CI $(0.42,0.71)])$ less likely to consume alcohol compared to students who were truant at least 3 days in the previous one month to the survey. While students who rarely received parental supervision were more likely (AOR=1.85 [95\%CI $(1.19,2.90)]$ to consume alcohol compared to students who always received parental supervision, those students who sometimes received parental supervision were less likely $(\mathrm{AOR}=0.70$ [95\%CI $(0.50,0.98)]$ to consume alcohol.

\section{Discussion}

In a study of school-going adolescents in Harare, Zimbabwe, we found that in the past 12 months $14.8 \%$ of the students felt lonely most of the time or always, $13.1 \%$ could not sleep because of worries, while $21.6 \%$ had seriously considered committing suicide. The 30 days reported prevalence of using alcohol was $15.6 \%$ overall; $17.1 \%$ and $14.0 \%$ among males and females, respectively.

In assessing factors that could be associated with alcohol use, we found that increased number of days that the teen had been bullied, lack of parental supervision most of the times and worry were positively associated with having used alcohol. Non-smokers were less likely to have used alcohol in the past 30 days.

Our results conform previous finding as to the factors associated with adolescent alcohol use. In a pooled analysis of GSHS data from 8 African countries, Brown et al. (2008) reported strong associations between bullying among youth and current alcohol use. Parental supervision of adolescents has been previously reported as protective against unhealthy behaviors among adolescents. It has been reported that parental supervision of adolescents may be protective against risky sexual behaviors (Rupp and Rosenthal, 2007).

Despite the use of a standardised research protocol, our study has a number of limitations. Perhaps importantly, we can not assign causation to any of the variables, e.g. just because bullying was associated with having used alcohol does not confirm that bullying victimization causes alcohol use. However, bullying could be stressful to the adolescent who may later engage in alcohol use as a way of coping with the stress. It is also possible that adolescents who take alcohol may frequently visit places where bullying is more likely to occur. However, we can only point to the associations without assigning any temporal sequence and causation.

Secondly, data were obtained through self-reports and alcohol use was not verified by any of the available biomarkers. To the extent that survey participants mis-reported, either intentionally or non-intentionally, our findings may bebiased. However, the GSHS methodology attempts to encourage truthful reporting by self-reporting (instead of being asked questions by an interviewer) and by not collecting any personal identifiers of study participants. This study also was restricted to data from Harare (the capital city) and may not be representative of the rest of the country. Finally, these data were collected from school-going adolescents and therefore may not be representative of all adolescent in the city.

In conclusion, prevalence of alcohol consumption among school-going adolescents in Harare, Zimbabwe is similar to what is reported from other African countries. There is a need to implement public health interventions with special attention to the determinants of alcohol consumption in this age group. 


\section{Acknowledgements}

We thank the World Health Organisation (WHO) for making these data available to us for analysis. However, neither the WHO nor the Centers for Disease Control and Prevention participated in the decision to analyse these data, our methods or decision to submit manuscript. Grateful thanks to all students and survey assistants who participated in the Harare, Global School Based Survey, 2003.

Received 30 July 2008

Revised 6 November 2008

Accepted 27 November 2008

\section{References}

Brown, D.W., Riley, L., Butchart, A. \& Kann, L. (2008) Bullying among youth from eight African countries and associations with adverse health behaviors. Pediatric Health 2, 289-299.

Clark, D.B., Martin, C.S. \& Cornelius JR. (2008) Adolescent-onset substance use disorders predict young adult mortality. Journal of Adolescent Health, 42, 637-639.

Degenhardt, L., Hall, W., Lynskey, M. \& WarnerSmith, M. (2004). Chapter 13. Illicit drug use. In Ezzati M, Lopez AD, Rodgers A, Murray R. (eds). Comparative Quantification of Health Risks: Global and Regional Burden of Disease Attributable to Selected Major Risk Factors. 2nd edition Geneva: World Health Organization. pp. 1109-1176.

Eide, A.H, Butau, T. \& Acuda, S.W. (1999) Adolescent drug use in Zimbabwe assessed by their teachers. Central African Journal of Medicine 45, 80-85.

Eide AH, Butau T, Acuda SW. (1999a). Use of alcohol and tobacco among secondary school teachers in Zimbabwe. Central African Journal of Medicine 45, 60-64.

Ezzati, M. \& Lopez, A.D. (2004) Chapter 11. Smoking and oral tobacco use. In Ezzati M, Lopez AD, Rodgers A, Murray R. (eds). Comparative Quantification of Health Risks: Global and Regional Burden of Disease Attributable to Selected Major Risk Factors. 2nd edition Geneva: World Health Organization. pp. 883-957.

Gwede, C.K., McDermott, R.J., Westhoff, W.W., Mushore, M., Mushore, T., Chitsika, E., Majange, C.S. \& Chauke, P. (2001) Health risk behavior of rural secondary school students in Zimbabwe. Health Education Behavior 28, 608-623.

Pitkänen, T., Kokko, K., Lyyra, A.L. \& Pulkkinen, L. (2008) A developmental approach to alcoholdrinking behaviour in adulthood: a follow-up study from age 8 to age 42 . Addiction 103 Suppl 1:48-68.

Poikolainen, K., Tuulio-Henriksson, A., AaltoSetala, T., Marttunen, M. \& Lonnqvist, J. (2001) Predictors of alcohol intake and heavy drinking in early adulthood: a 5year follow-up of 15-19 year-old Finnish adolescents, Alcohol and Alcoholism 36, 85-88.

Rome, E.S., Rybicki, L.A. \& Durant, R.H. (1998) Pregnancy and other risk behaviors among adolescent girls in Ohio. Journal of Adolescent Health 22, 50-55.

Rupp, R. \& Rosenthal, S.L. (2007) Parental influences on adolescent sexual behaviors. Adolescent Medicine: State of the Art Reviews 18, 460-470.

Santelli, J.S., Brener, N.D., Lowry, R., Bhatt, A. \& Zabin, L.S. (1998) Multiple sexual partners among U.S. adolescents and young adults. Family Planning Perspectives 30, 271-275.

Valois, R.F., Oeltmann, J.E., Waller, J. \& Hussey, J.R. (1999) Relationship between number of sexual intercourse partners and selected health risk behaviors among public high school adolescents. Journal of Adolescent Health 25, 328-335.

World Health Organization. (undated). Global School-based Student Health Survey www.who.int/chp/gshs 